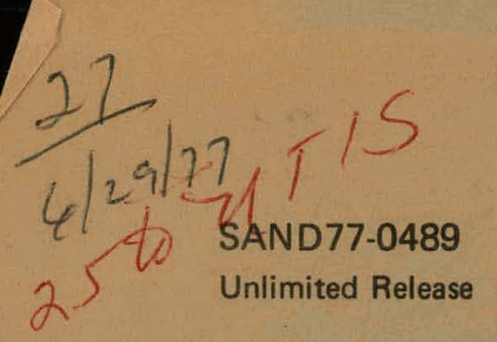

\title{
An Approach for Evaluating Alternative Future Energy Systems: A Dynamic Net Energy Analysis
}

John L. Mitchiner, Virgil L. Dugan, Samuel G. Varnado

Prepared by Sandia Laboratories. Albuquerque New Mexico 87115

and Livermore, California 94550 for the United States Energy Research

and Development Administration under Contract AT (29-1) 789

Printed May 1977

OISTRIBUTION OF THIS DOCUMENT IS UMLIMITED

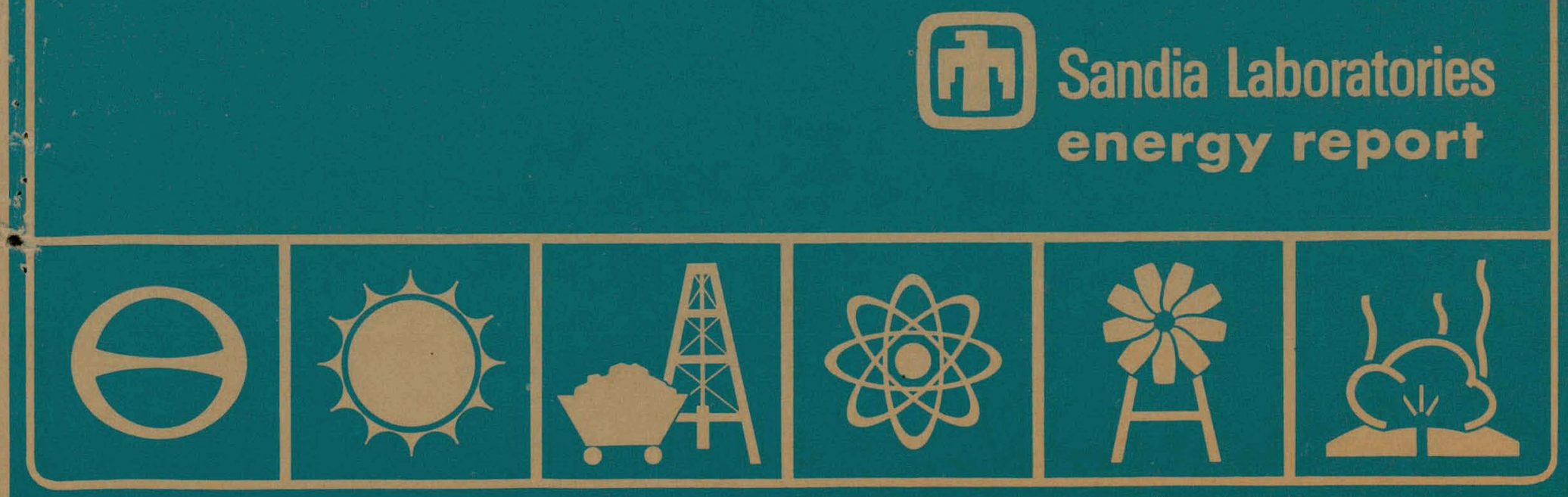




\section{DISCLAIMER}

This report was prepared as an account of work sponsored by an agency of the United States Government. Neither the United States Government nor any agency Thereof, nor any of their employees, makes any warranty, express or implied, or assumes any legal liability or responsibility for the accuracy, completeness, or usefulness of any information, apparatus, product, or process disclosed, or represents that its use would not infringe privately owned rights. Reference herein to any specific commercial product, process, or service by trade name, trademark, manufacturer, or otherwise does not necessarily constitute or imply its endorsement, recommendation, or favoring by the United States Government or any agency thereof. The views and opinions of authors expressed herein do not necessarily state or reflect those of the United States Government or any agency thereof. 


\section{DISCLAIMER}

Portions of this document may be illegible in electronic image products. Images are produced from the best available original document. 
Issued by Sandia Laboratories, operated for the United States Energy Research \& Development Administration by Sandia Corporation.

\section{NOTICE}

This report was prepared as an account of work sponsored by the United States Government. Neither the United States nor the United States Energy Research \& Development Administration, nor any of their employees, nor any of their contractors, subcontractors, or their employees, makes any warranty, express or implied, or assumes any legal liability or responsibility for the accuracy, completeness or usefulness of any information, apparatus, product or process disclosed, or represents that its use would not infringe privately owned rights. 


\title{
SAND 77-0489 \\ Unlimited Release \\ Printed April, 1977
}

\author{
An Approach \\ for Evaluating Alternative \\ Future Energy Systems: \\ A Dynamic Net Energy Analysis
}

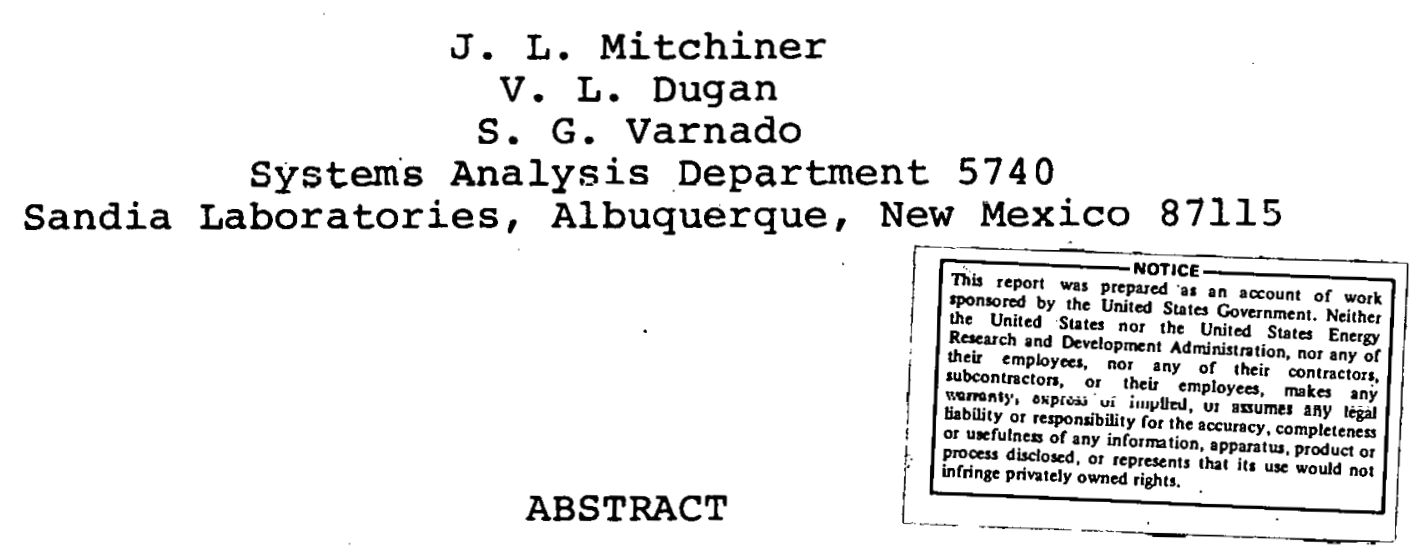

Realistic analysis of future energy systems is a difficult, but crucial, component of assuring future energy supplies. The procedure proposed in this paper is a dynamic, net energy assessment that is a resource-based method for evaluating future energy systems. The model is system, site and application specific and is equally applicable to general system characterizations and specific designs. The implications of possible resource and societal constraints on energy development are investigated. 


$\begin{array}{lr}\text { Introduction } & \frac{\text { Page }}{7} \\ \text { Model Description } & 12 \\ \text { Examples } & 21 . \\ \text { Conclusions and Recommendations for Future Work } & 34\end{array}$

\section{FIGURES}

Figure

1. A Resource View of Energy Development

2. Dynamic Net Energy Analysis Model Flowchart

3. Direct Use Power Availability for Three

Electrical Power Generation Systems;

A 100 Year Optimization

4. Optimal Energy Reinvestment for Three Electrical Power Generation Systems

5. Direct Use Power Availability. with a Constrained Feedback Strategy for Two

Electrical Power Generation Systems;

A 100 Year Optimization

6. Direct Use Power Availability for Three

Electrical Power Generation Systems;

A 50 Year Optimization

7. Relative Energy Efficiencies Over a 150 Year Conditioning Cycle

8. Optimization of solar system A over 100 Years for Resource Lifetimes of 20 and 100 Years

9. Mineral/Materials Resource Implications for Three Electrical Power Generation Systems

TABLES

Table

I. Definitions of Model Parameters

II. General Model Formulation

III. Parameter Values for Three Electrical Power Generation Systems 
AN APPROACH FOR EVALUATING ALTERNATIVE FUTURE ENERGY SYSTEMS: A DYNAMIC NET ENERGY ANALYSIS

\section{Introduction}

World energy resources can no longer be considered inexhaustible. It is clear that in the next century the U.S. will be approaching at least some of its energy resource limits, unless new energy technologies are developed. Rising costs and decreasing efficiencies of oil and natural gas discovery and recovery are current indications of these approaching limits.

Viable alternatives to conventional energy sources must be developed soon. World political and economic stability hinges on a smooth transition to new energy sources. Price increases resulting from the 1973 oil embargo illustrate that even relatively modest price changes and short discontinuities in availability can wreak economic havoc throughout the world. The development of energy sources from concept to commercial operation requires decades, and significant market penetration requires additional decades. Each energy source that is developed through this process requires resources of money, manpower, and energy.

Theoretically, the number of future energy alternatives is almost unlimited, with none exhibiting clear advantage over the others. The number of possible solutions is a major aspect of the problem. In addition to the large number of basic energy sources to choose from (fast breeders, photovoltaics, solar-thermal, wind, etc.), there are a great many permutations on plant design that can affect the plant economic viability. Size and type of energy storage, 
and whether to use high temperature, high technology energy conversion are examples.

The decision process is further clouded by the spectrum of power and energy loads that must be met. For example, for fixed site electrical power producers one can consider base loads, intermediate loads, and peaking loads. Each of these loads presents unique system requirements which could potentially be satisfied by a large number of system configurations.

Finally, the plants must be viable 20 to 30 years hence, which may not be equivalent to current economic viability. This is the main problem associated with evaluating future energy sources with present economic techniques, e.g., discounted cash flow. These techniques require the assumption that our economy is stationary or at least predictable. These assumptions may be negated by unpredictable short term fluctuations and by more pervasive long term trends. Short term fluctuations include tax rates, tax incentives, interest rates, inflation rates, material costs, etc. The long term trends may be more crucial. Energy costs, today, are still a small fraction of the total economy. As energy resources are consumed, they will become scarcer, and energy costs will become a larger fraction of our total economy. In this case, capital cost estimates made today will probably be totally unrealistic 20 years hence. For example, it may be currently economic to use plastic in a solar system design (and some do). Only 138 of the wholesale price of plastic, an energy intengive material, can be currently traced to energy costs. 1 As fossil resources are depleted, energy costs must become more important; this can significantly change the economic basis for a discounted cash flow analysis. It is, therefore, instructive to consider more fundamental approaches to the analysis of alternative energy sources. 
Net energy analysis is a useful tool for examining the transition from energy resource to conditioned (e.g. electrical) energy. The end result of a net energy analysis is the ratio of the energy produced by the system to the energy required to build and operate the system. There are currently three main approaches to net energy analysis. A process analysis is a detailed energy accounting method that follows the energy flows through plant construction and operation: Major secondary energy flows are analyzed and included. Energy Input/Output analysis, which is based on economic Input/Output analysis, concerns itself with energy transactions between sectors, and arrives at an appropriate energy intensiveness (Btu/Dollar).2 Ecoenergetics is by far the most encompassing approach, as it includes nature's free subsidies, as well as the energy flows associated with human activity. ${ }^{3}$. Neither the process analysis nor the energy I/O models usually include the energy contained in the resource. In the authors' opinion, this is reasonable only when analyzing a system that does not require depletable resources. If the resource is depletable, that energy is a valuable commodity, and that energetic value must be included in the analysis. In addition, the results of these types of. net energy analyses can be difficult to interpret in a plan-. ning sense. The Energy Output/Energy Input ratio is a static approximation of a dynamic process.

The purpose of this work is to suggest another approach to analyzing energy systems that incorporates the results of a net energy analysis into a dynamic framework. A simple, dynamic model based on resource considerations and energy efficiencies, rather than capital economics, will be developed.

Figure 1 is a resource based view of energy development. Raw mineral/material resources, as well as energy resources, are required to develop and operate energy systems. Both resource types must be conditioned. stored energy reserves, 


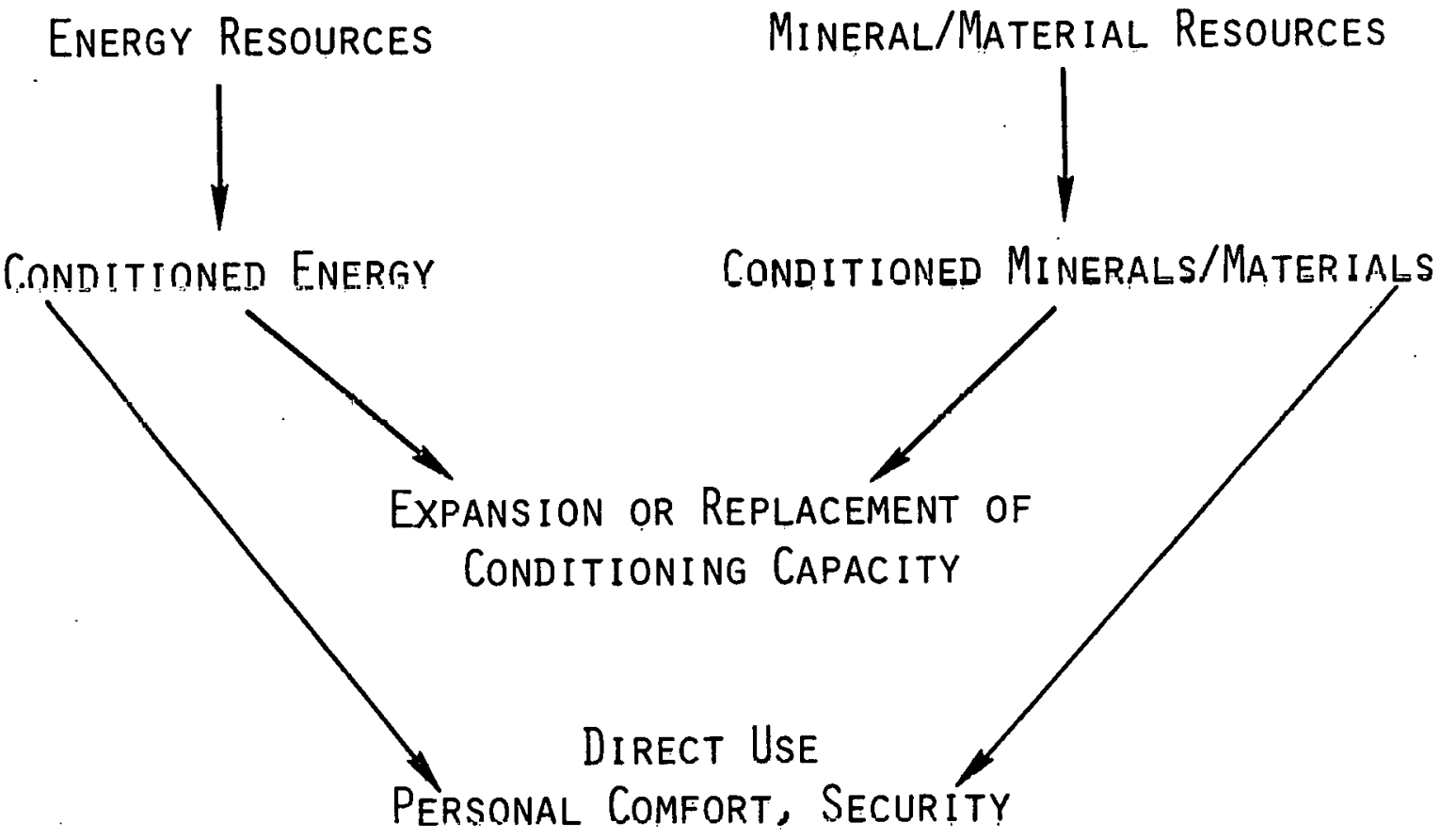

Figure 1. A Resource VIEW OF ENERGY DEVELOPMENT 
e.g., coal and uranium, are converted to steam and then into electrical power. Mineral ores are similarly processed to increase their purity, formed into structural components and fabricated into power plants. The conditioned (electrical) energy output can then be used in two ways. The energy can be used directly to increase society's personal comfort and security. This is the traditional way to think of end use power consumption. A second use for the energy, not usually considered, is to feed some energy back into the expansion or replacement of conditioning capacity. This direct link between the existing energy conditioning capacity and the ability, to expand capacity should become more important as existing stored reserves are depleted. Note that energy.used to expand future capacity is taken directly from the energy available for personal use. It can be likened to an energy investment.

The model will be used to maximize, over a fixed planning period, the ratio of energy made available for direct use to the energy extracted from stored reserves. This model is able to illustrate several important, dynamic characteristics of developing energy systems. The optimal development of future energy technologies and their required energy resources can be determined, and the time integral of the ratio of energy produced to energy consumed for the period of interest can be calculated. Also, the net results of increased plant efficiency at the expense of increased initial energy investments can be examined." The large energy investments required and the transition dynamics of the process of becoming independent of dwindling energy resources can also be illustrated.

In the present state of the analysis the mineral and material resource requirements will be ignored, although the authors contend that they are important and should be included 
in further analyses. Current efforts in advanced energy technologies emphasize future energy sources that have relatively inexhaustible fuel supplies, e.g., fast breeders, fusion, solar, wind, etc. This approach appears reasonable because the limits on fuel resources are becoming very apparent. Mineral/material resource limits are not currently as obvious, but the limits are just as real and must be considered in the analysis of future energy systems.

Model Description

The model flow chart is found in Fiyure 2. The system is described by a single, first order difference equation and an algebraic output equation. The time step is nominally chosen as one year. The unconditioned collection/conversion capacity is the state variable, $P_{C}$. The unconditioned collection/ conversion capacity $\left(\mathrm{MW}_{t h}\right)$ is the maximum thermal output power available from the energy source being evaluated. The power required to construct unconditioned capacity is supplied by the power extracted from stored reserves and from the reinvested conditioned output power. The power from stored reserves, $\mathbf{P}_{\mathbf{s}}$ ( $\left(\mathrm{MW}_{\mathrm{th}}-\mathrm{Yr} / \mathrm{Yr}\right)$ is defined as the energy extracted from any depletable energy resource during one year. $P_{S}$ is modified by three parameters $-F(K), \eta_{1}$ and $\tau_{1}, F(K)$ is the fraction of the available resource that is required to fuel existinq power plants. For fuel consuming powex plante, the power output is fuel limited. If all the available resource power is used for fuel, none is available for constructing new capacity. $F(K)$ is a variable and will change each year depending on the existing power plant fuel requirements. $\eta_{1}$ is the efficiency of converting energy resources to unconditioned power generation capacity. $\eta_{1}$ must include mining, processing and fabricating everything associated with constructing additional power generation capacity. 


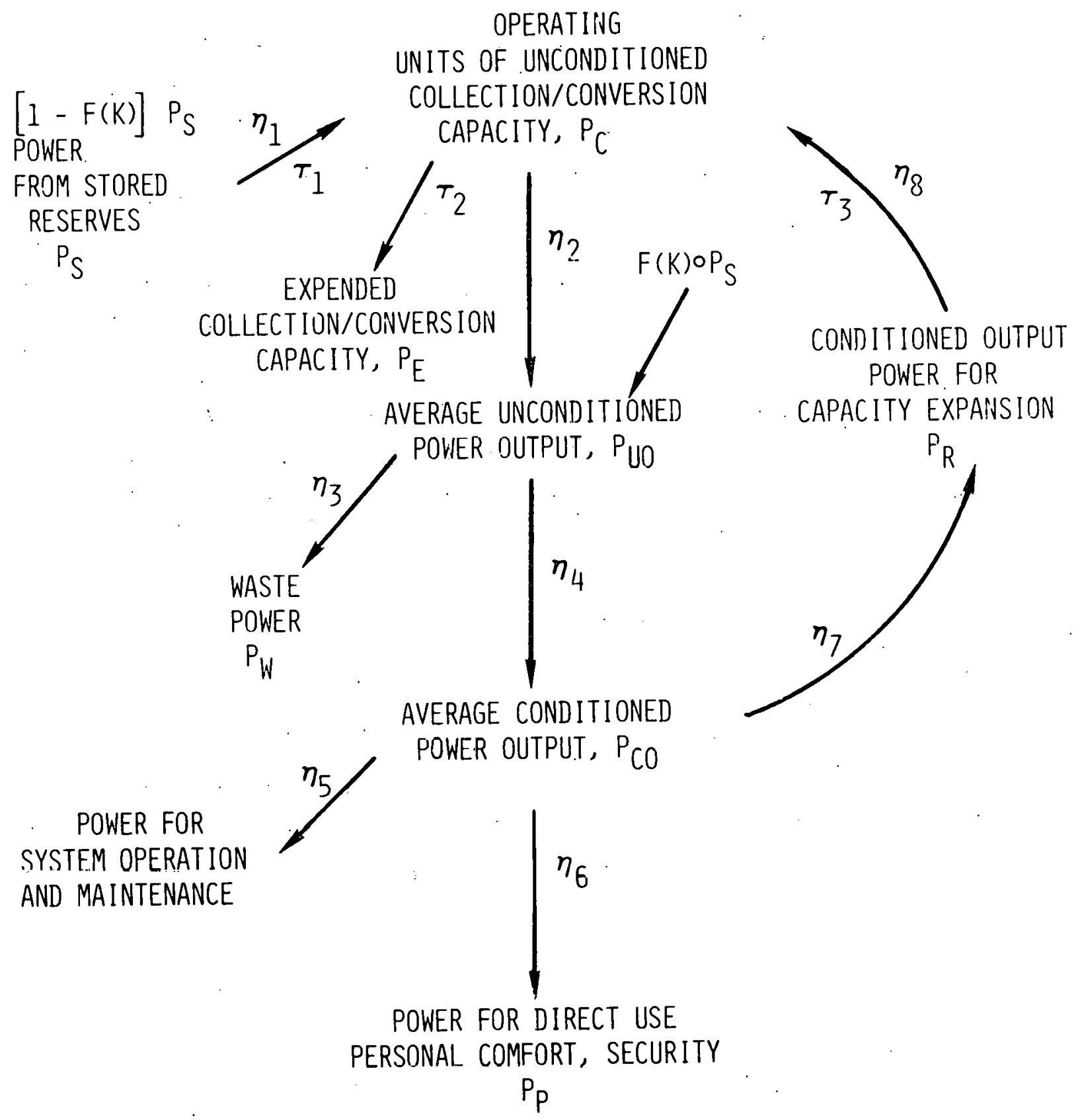

Figure 2. Dynamic Net Energy Analysis Model Flowchart 
This efficiency is calculated with a net energy analysis. $\tau_{1}$ is the time required to convert energy resources into operating unconditioned capacity. $\tau_{1}$ includes plant construction time. $\eta_{1}$ and $\tau_{1}$ are functions of the specific plant design. For instance, adding storage to a solar system will decrease the conversion efficiency due to the increased construction required for the same capacity and may increase $\tau_{1}$ due to longer construction times. Similar results occur if direct conversion, for example MHD, is added to the system to increase the efficiency of converting thermal power to electrical power.

The expended collection/conversion capacity, $\mathrm{P}_{\mathrm{e}}$, is the plant capacity that has operated for a full lifetime and has been removed from the system. $\tau_{2}$ is the plant operating lifetime.

The unconditioned power generation capacity is transformed into an average unconditioned power output, $\mathrm{P}_{\text {uo' }}$ by an efficiency, $n_{2} \cdot n_{2}$ is the plant availahility and is defined as llie l.ifetime power produced divided by the potential lifetime power produced if the system could be continually operated at full capacity. For a light water reactor, $\eta_{2}$ is a function of scheduled and unscheduled downtime for operation and mantchance and additional time thit the plant cannot oporatc at full power. For a sulal systell, $\eta_{2}$ is a function of the sunlight availability, average power/maximum power output ratio, and unscheduled downtime. In most solar systems the average power/maximum power ratio is a function of energy storage. In general, the more storage, the higher the ratio of average power to maximum power. Scheduled downtime for operation and maintenance is not included in a solar system because it is assumed that scheduled work will be done during normal nonoperative periods, e.g. at night. 
If the plant being evaluated requires fuel from stored reserves, the average unconditioned power will be limited by the fuel supplies.

The average unconditioned power output is converted to average conditioned power output with an efficiency, $n_{4} \cdot$ $n_{4}$ is a thermodynamic efficiency and is primarily a function of operating temperature. $\eta_{4}$ may be increased in some cases by using direct conversion schemes (MHD). Recall, however, this is at the expense of a lower $\eta_{1}$ and possibly longer $\tau_{1}$. $\eta_{3}$ is the fraction of unconditioned power that is wasted.

The average conditioned power output may be consumed in three ways. $n_{5}$ siphons off the fraction of the output power that is required to keep the system operating. The value of $\eta_{5}$ for a specific system can be determined from a net energy analysis. In a broad sense, it is the recirculating power fraction. For example, in a nuclear plant, the mining, milling and enriching. of the fuel must be included as well as the plant recirculating power fraction.

$\eta_{7}(K)$ is the fraction of the conditioned output power that is reinvested to construct new units of collection/conversion capacity. $n_{7}(K)$ is the model control variable that is adjusted to maximize the power available for direct personal use. The conditioned output power available for capacity expansion is used to construct new capacity with an efficiency, $n_{8}$, and associated time lag, $\tau_{3}$. There is a strong parallel between $\eta_{8}, \tau_{3}$ and $\eta_{1}, \tau_{1}$. The only difference is that the conditioned output power is a higher quality energy source than the energy extracted from stored reserves to build new capacity. One might expect $\eta_{8}$ to be three times $\eta_{1}$, since that is the conversion efficiency from thermal to electrical power. This is not the case because only a fraction of the power used to build new plants requires high quality electricity. The 
conditioned output power may be no more efficient than the stored reserve power at providing process heat. $\eta_{8}$ may also be determined from a net energy analysis.

The conditioned output power that remains after power is removed for system operation and maintenance and for generating new capacity is available for personal use. This fraction of the conditioned output power is denoted $n_{6}$. The power available for personal use is the only product that can contribute to maintaining or improving society's quality of life. All else is either waste or required for maintaining present or future supplies of energy. The power available for personal use is maximized uver a planning period with respect to a fixed rate of resource consumption by varying $n_{7}(K)$. Table I lists a summary of the parameter definitions.

The equations and performance index used in optimizing the model are presented in Table II. The selected performance criteria is the summation of the natural log of the personal use puwer produced, given a planning period and rate of resource consumption. This criteria is used because it equally weights each year's contribution to the summation, if the system grows exponentially. This index provides a personal power production trajectory that appears acceptable. If, instead, the performance criteria were simply the summation over time of the direct use power production, the optimized control strategy would be to feed all tlie power produced into exponential growth until the final years of the optimization where huge quantities of personal use power are produced. Clearly this is an unacceptable trajectory. The criteria chosen is reasonable and appears suitable for this analysis. The applicability of this criteria is probably not unique, so the usefulness of other criteria should be investigated further. 
TABLE I.

DEFINITIONS OF MODEL PARAMETERS

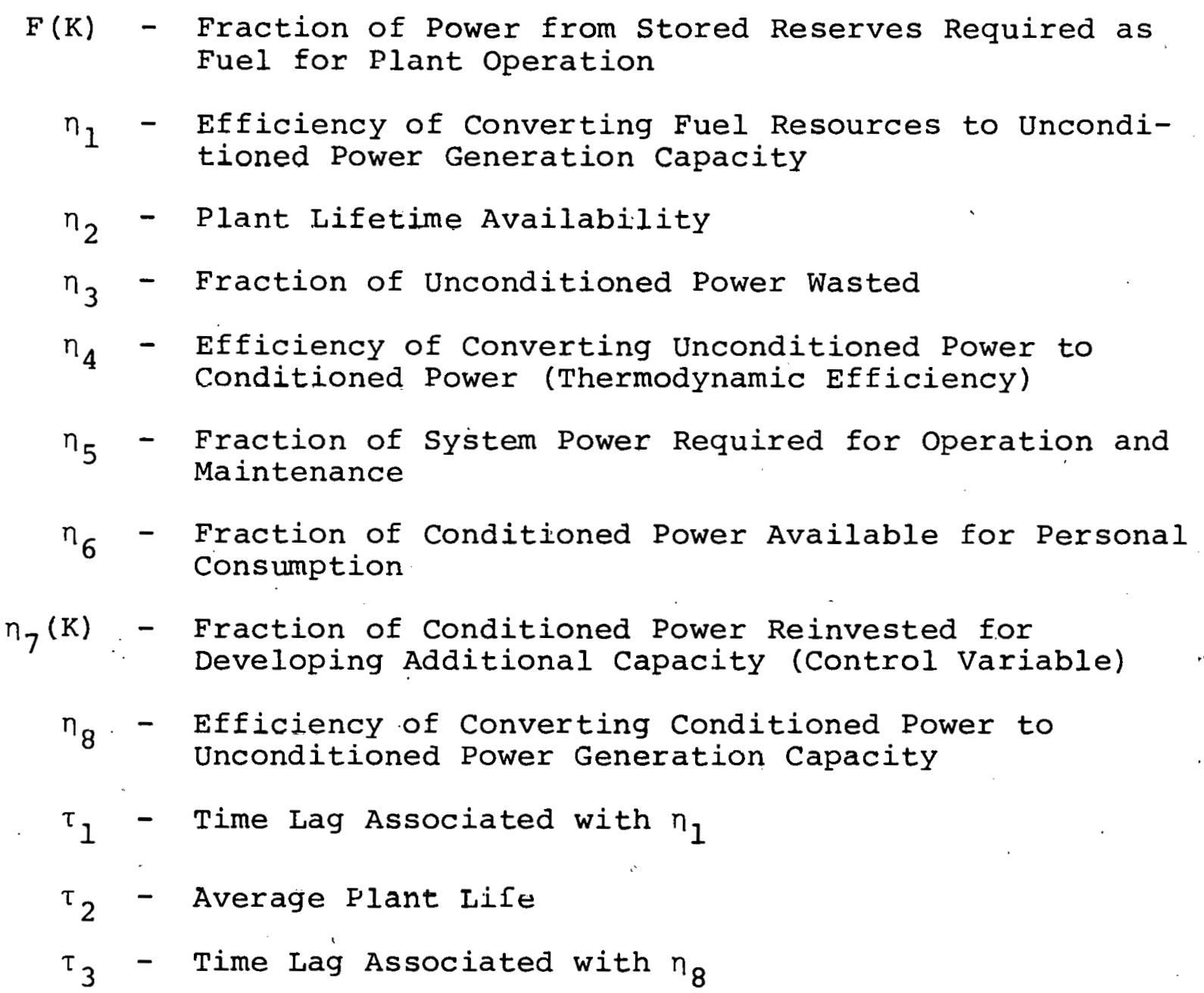


TABLE II.

GENERAL MODEL FORMULATION

$$
\begin{aligned}
& P_{C}(K)=P_{C}(K-1)+\eta_{1}\left[I-F\left(F-\tau_{1}\right)\right] P_{S}\left(K-\tau_{1}\right)-\left(P_{C}\left(K-\tau_{2}\right)-P_{C}\left(K-\tau_{2}-1\right)\right) \\
& +\operatorname{MIN}\left\{\begin{array}{l}
\urcorner_{2} \eta_{4} \eta_{7}(K) \eta_{8} P_{C}\left(K-\tau_{3}\right) \\
\Xi\left(K-\tau_{3}\right) \eta_{4} \eta_{7}(K) \eta_{8} P_{S}\left(K-\tau_{3}\right)
\end{array}\right\} \begin{array}{c}
\text { VARIABLE } \\
F(K)
\end{array} \\
& P_{C}(K)=P_{C}(K-1)+r_{1} P_{S}\left(K-\tau_{1}\right)-\left(P_{C}\left(K-\tau_{2}\right)-P_{C}\left(K-\tau_{2}-1\right)\right) \\
& +\eta_{2} \eta_{4} \eta_{\nabla}(K) \eta_{\varepsilon} P_{C}\left(K-\tau_{3}\right) \quad F(K) \equiv 0 \\
& P_{F}(K)=\operatorname{MIN}\left\{\begin{array}{ccc}
\eta_{2} \eta_{4} \eta_{6} & F_{C}(K) \\
F(E) \eta_{4} \eta_{6} & P_{S}(K)
\end{array}\right\} \begin{array}{c}
\operatorname{VARTABLE} \\
F(K)
\end{array} \\
& P_{P}(K)=\eta_{2} \eta_{4} \eta_{6}{ }^{F}{ }_{C}(K) \quad F(K) \equiv 0
\end{aligned}
$$

$\underset{\text { CRITERIA }}{\text { PERFORMANCE }}=$ MAX $\left\{\sum_{t}\right.$ ln $\left.P_{P}\right\} \quad$ FOR A GIVEN $P_{S}$ 
The planning period, which is the number of years included in the optimization, can have a large effect on the resulting optimal strategy. At one extreme, if the planning period is one year, no power reinvestment ever occurs. AlI power produced is consumed. In general, the longer the planning period, the more power reinvested in future power generation capacity.

Several observations on the characteristics of this model should be made. The approach is system specific. In the examples that follow, two solar systems and a light water reactor are characterized in a general sense. Although this broad type of characterization can be useful, the model is equally adaptable to evaluating specific system designs. Two systems that are very similar, except that one substitutes a great deal of plastic for iron, may have very different evaluations. $\eta_{1}$ and $\eta_{8}$ ' the energy construction efficiencies, would be different, while all the other system efficiencies would remain constant. Another example would be to evaluate a solar system with and without energy storage. Storage would have the effect of lowering $n_{1}$ and $n_{8}$ while increasing $n_{2}$. The implications of this type of tradeoff would be difficult to analyze without using a dynamic model.

Secundly, the model is site specific. $\eta_{2}$, the system availability, will be a strong function of site for solar and wind systems. Less strongly, all systems analyzed will be a function of the distance to fuel supplies or the source of construction material or the labor pool. Site selection could also be important in analyzing sites near population or industrial centers where the waste heat could be used as process heat.

The model is also application specific. For instance, a rlat plate solar thermal system should be better suited to producing relatively low temperature process heat than 
it would be for producing electricity. For producing process heat, ${ }_{4}$ may be 1 , while for electricity it is approximately 0.15 .

This model is sensitive to the values of the model parameters because of the feedback within the model. Energy systems are usually analyzed statically, but dynamic considerations are important. The actual system is sensitive to the efficiencies. A difference in efficiency that appears small in a static sense, may not be small when evaluated as an oxponcntial growth factor. Fur example, glven two 1dentical plants, additional conditioned output power produced by one that is more efficient can be fed bạk to sonstruct new power generation at no penalty. This process is exponential. Therefore, it is critical that the parameters be determined accurately before ranking alternative systems. Because of this extreme sensitivity, system comparisons should include evaluation of the parametric sensitivities of the system and estimates for the accuracy of the model parameters.

The control strategy for each alternative system is determined by maximizing the performance index. System evaluations made by this moiel rely on following this procaribed control strategy. If the control strategy is believed to be unacceptable, the control variable, $\eta_{7}$, must be bound to reasonable limits. The fraction of the output power required for system growth or maintenance can be large and, if so, it may be difficult to meet future power demands without the benefits of large resources.

Finally, the implications of the size of the resource base and the manner in which it is depleted can be investigated. The longer a new energy technology can be subsidized by existing high quality resources, the more likely the transition to new sources can be made smoothly and with no discontinuities in 
energy availability. The difficulty is that subsidizing new technologies with existing energy supplies represents an investment for the future. with no current return.

\section{Examples}

Three electrical power generation systems are modeled and optimized to illustrate the proposed procedures. They are representative of a solar tracking, focused collector system (Solar A), solar flat plate collector system (Solar B) and a light water reactor (Fission). The system parameters are given in Table III. These parameters should only be treated as representative of the system type.

$\eta_{1}$ represents the energy conversion from resource to unconditioned capacity. It varies by a factor of 4 from Solar A to Fission. The fission system is by far the most efficient convertor of resources to capacity. 4 The relationship between the solar systems is as expected, since the tracking collector system is more sophisticated and requires a larger energy investment. $n_{2}$, the plant availability, is also significantly different between systems. The fission plant is available $71 \%$ of the time; Solar $A 25 \%$ of the time; and Solar B $16 \%$ of the time. $\eta_{2}$, for solar A is the product of $75 \%$ cloudless days, $37 \%$ average power/maximum power, and $90 \%$ availability due to unscheduled downtime. These are typical numbers for Albuquerque, New Mexico. $n_{2}$, for Solar. $B$, differs only in that the average power/maximum power ratio is 23\%. $\eta_{2}$, for all systems, is based on the assumption that whenever power is produced, it is consumed. $n_{4}$ ' the thermodynamic efficiency, is indicative of the different operating temperatures. The fission system recirculating power fraction, $n_{5}$, includes the energy required for the fuel enrichment process. $4 n_{8}$ is the conversion factor from output electrical power to new capacity. Electrical power has a 3 to 1 advantage 
PARAMETER VALUES FOR THREE ELECTRICAL POWER GENERATION SYSTEMS

\section{ELECTRIC POWER GENERATION SYSTEM}

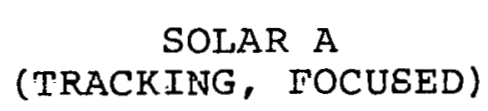

.8

$n_{1}$

$n_{2}$

$n_{3}$

$n_{4}$

$n_{5}$

$n_{6}$

$n_{7}$

$n_{8}$

$\tau_{1}$

$\tau \dot{2}$

$\tau_{3}$

$F(K)$

.1

$1 \cdot n_{5}-n_{7}$

Variable

1.0

3

30

3

0
SOLAR B

(FLAT PLATE)

1.1

.16

.85

.15

.1 $1-n_{5}-n_{7}$

Variable

1. 3

3

30

3

0
NUCLEAR

FISSION

3.1

.71

.60

.32

.07

$1-n_{5}-n_{7}$

Variable

3.7

7

30

7

Variable 
over thermal power when electricity is required.for plant construction. There is no advantage to electrical power when thermal energy is required. The net energy analysis used to calculate the fission model parameters ${ }^{4}$ explicitly listed thermal and electrical power requirements. $n_{8}$ was directly calculated using that information. Similar information was not available for the solar systems, so the $n_{1} / n_{8}$ ratio used for fission is also assumed for solar. The construction times are considered to be 3 years and 7 years for the solar systems and the fission system, respectively. It is assumed that the solar plants will be smaller and more conventional in nature than the fission system and require less construction time. All plants operate for 30 years. Only the fission system requires resource power for fuel.

The power produced for direct use by all three systems is optimized by performing a pattern search over the possible values for $n_{7}(k) .5$ This control variable is considered to be piecewise constant over 5 year intervals. Each five year increment of $\eta_{7}(K)$ is treated as an independent variable from all other values of $\eta_{7}(K)$. Although the technique is rather crude, it offers several advantages. The method is simple and easy to apply. It is quick, requiring less than 20 seconds of computer time per 100 year optimization on a CDC 6600. Constraints on $\eta_{7}(K)$ can be easily applied if desired. A problem with using a pattern search is that it does not guarantee finding a global maximum. More sophisticated optimization techniques may be applied in future studies.

Post optimization values of $n_{7}(K)$ were desired to investigate the system dynamics after the optimization period. For Solar $A$, the $\eta_{7}(K)$ values resulting from the optimization were fit to a logistic curve to arrive at an asymptote. This procedure was not appropriate for solar $B$; so the value of $\eta_{7}(K)$ at the end of the optimization period is used for later years. 
The resource consumption for the solar systems begins in year $t=-2$, so that power production can begin in the first year of the optimization. The fission system is initialized so that all of the resource power is consumed as fuel. The systems are treated differently because the fission system is currently operating on a large scale basis; solar is not.

Direct use power consumption optimized over 100 years is shown for the three systems in Figure 3. The associated feedback strategy is presented in Figure 4. The resource power available is arbitrarily chosen to be 1 unit per year for 100 years and zero thereafter. One unit of resource power is defined as one unit of thermal power when used as light water reactor fuel. If the resource power is defined in an absolute sense (total available fission energy), the fission reactor power would be $1 / 130$ of that shown. Solar A is able to become independent of energy resource consumption and continue to grow after the resources become unavailable. In order to accomplish this growth a large fraction of the power produced must be reinvested in new plant construction. Only about $25 \%$ of the conditioned output power is available for direct use. Solar B is unable to become independent of resource consumption. The efficiencies assumed for this system are too low to effectively produce electricity. Note that the arop in power available for direct use in the last 20 years of the optimization coincides with power being reinvested for future construction. No power is fed back to construction for the first 80 years because the efficiencies are so low that it is better to simply use it when produced.

Direct use power from the fission system remains relatively constant, producing electrical power at approximately a $28 \%$ overall efficiency. The light water reactor system is almost completely fuel limited. The small transients in the direct use power production curve result from small amounts of power being fed back for new construction. When the fuel resource is not available, fission power production ceases. 
PERSONAL POWER CONSUMPTION

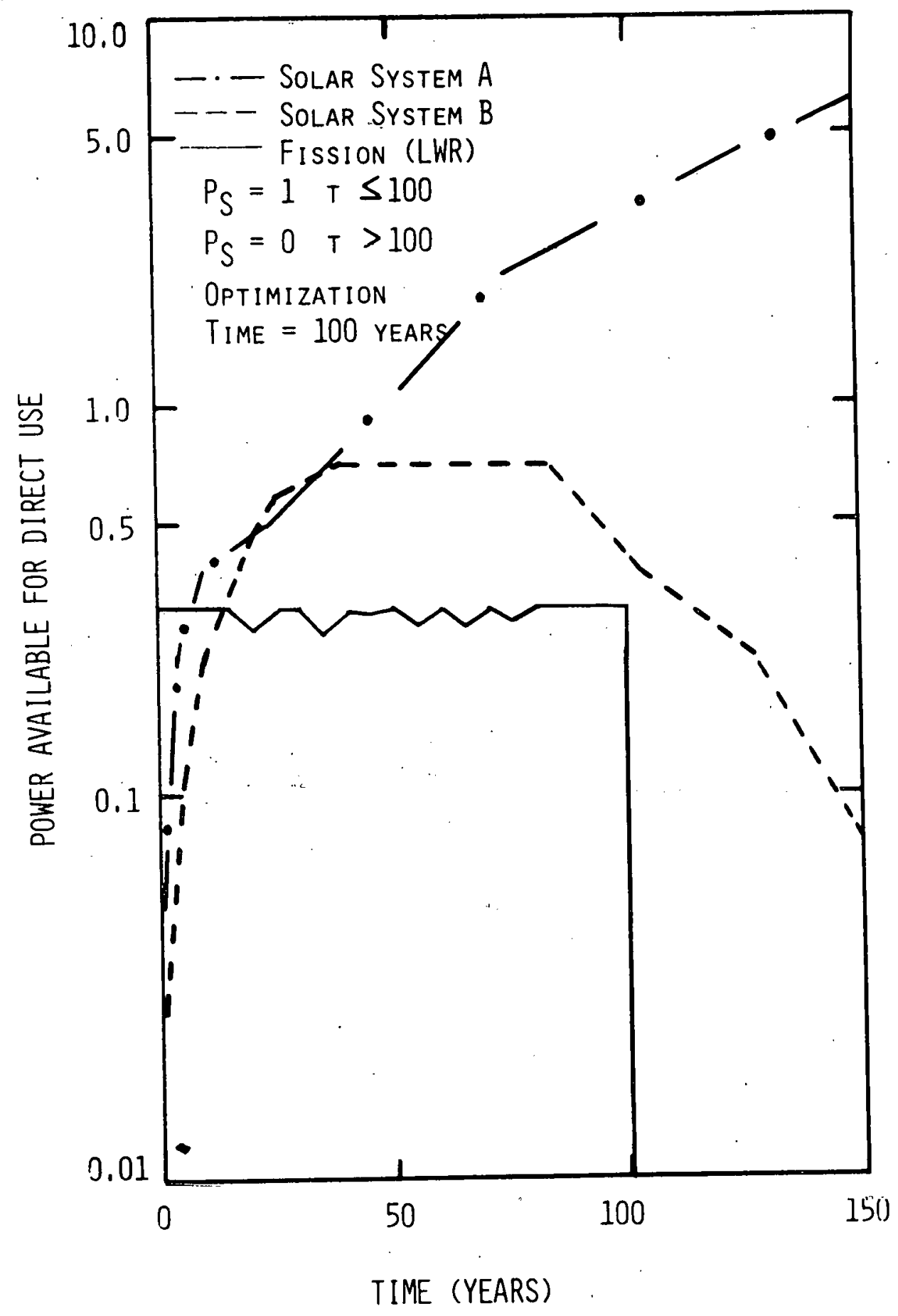

Figure 3. Direct Use Power Availability for Three Electrical Power Generation Systems; a 100 Year Optimization 


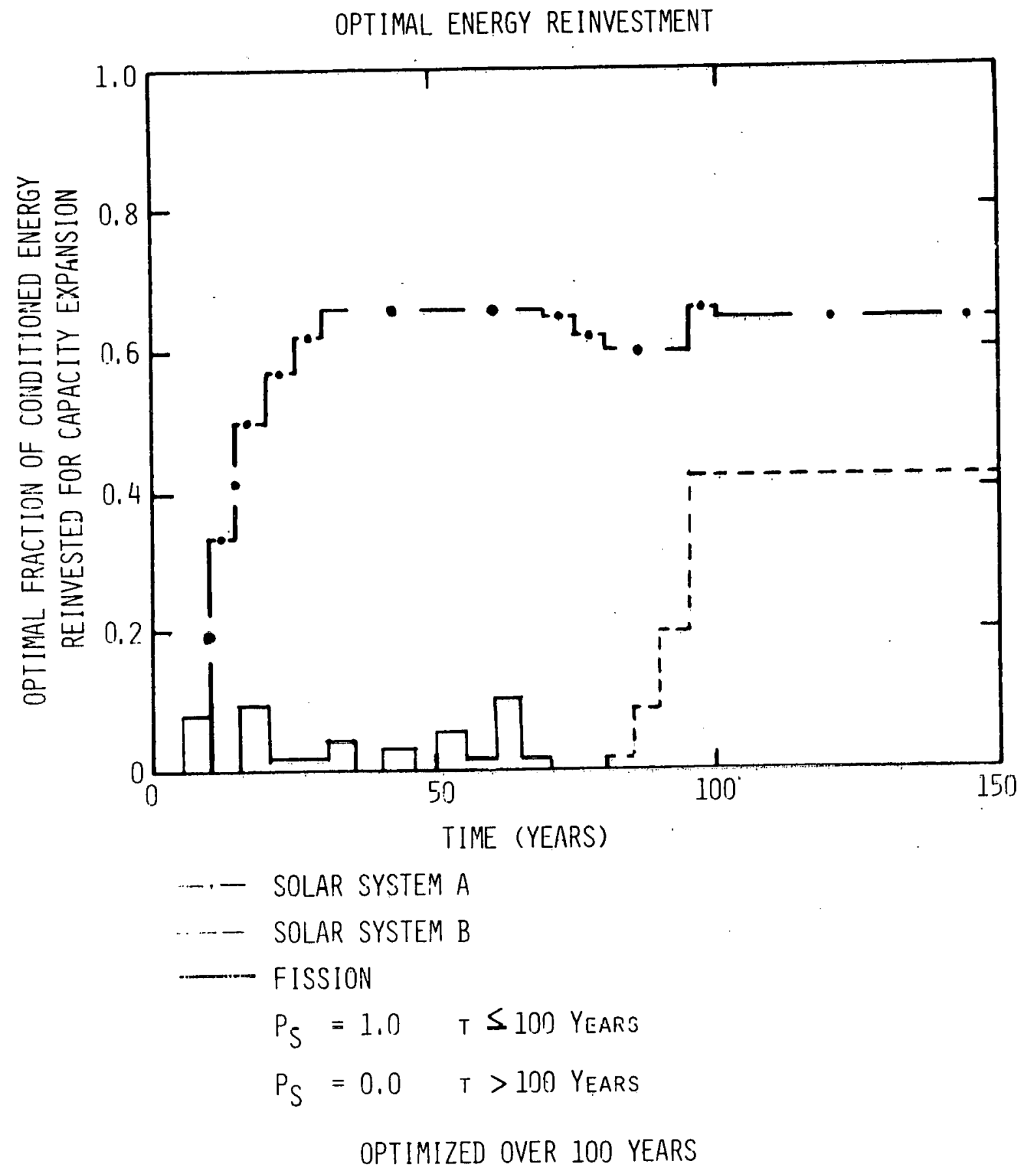

Figure 4. Optimal Energy Reinvestment for Three Electrical Power Generation Systems 
An interesting insight may be gained by examining the feedback characteristics of Solar A and Fission. The optimal fission feedback average is small ( 38) for the entire 100 years. The fission energy resource consumption is entirely dominated by fuel requirements. Solar $A$, on the other hand, requires a large fraction of its energy to be fed back into new construction. If a transition from fuel burning power sources to a system similar to solar $A$ is to be accomplished, entirely new thought processes on energy production may be required. Specifically, much larger fractions of energy production will be diverted from personal use to expanding and maintaining power generation capacity; thus less power will be available for personal consumption.

The effect of reinvesting less than the optimally determined amount of output power is illustrated in Figure 5. Here, the feedback variable, $\eta_{7}(K)$, is limited to 108 of the conditioned output power. Solar $A$ is particularly affected. Under a limited reinvestment policy, even Solar A is unable to become independent of energy resource consumption. Although limiting feedback to $10 \%$ may seem low, the average optimal fission feedback was $3 \%$. Using the limited feedback policy, Solar B decays even faster than previously.

Figure 6 illustrates the effect of altering the planning period (optimization time). The model is the same as shown in the 100 year optimization, Figure 3 . For all systems, $n_{7}(\mathrm{~K})$ is not as high as in the 100 year optimization. As a result, Solar A appears to be reaching a maximum power production rather than continuing growth. At the end of the 50 year optimization period, Solar B begins to reinvest significant quantities of output power into power generation. The downward trend around 50 years is a result of the reinvested power being taken away from the direct use power. The temporary ensuing growth is. a result of that investment. Ultimately, 


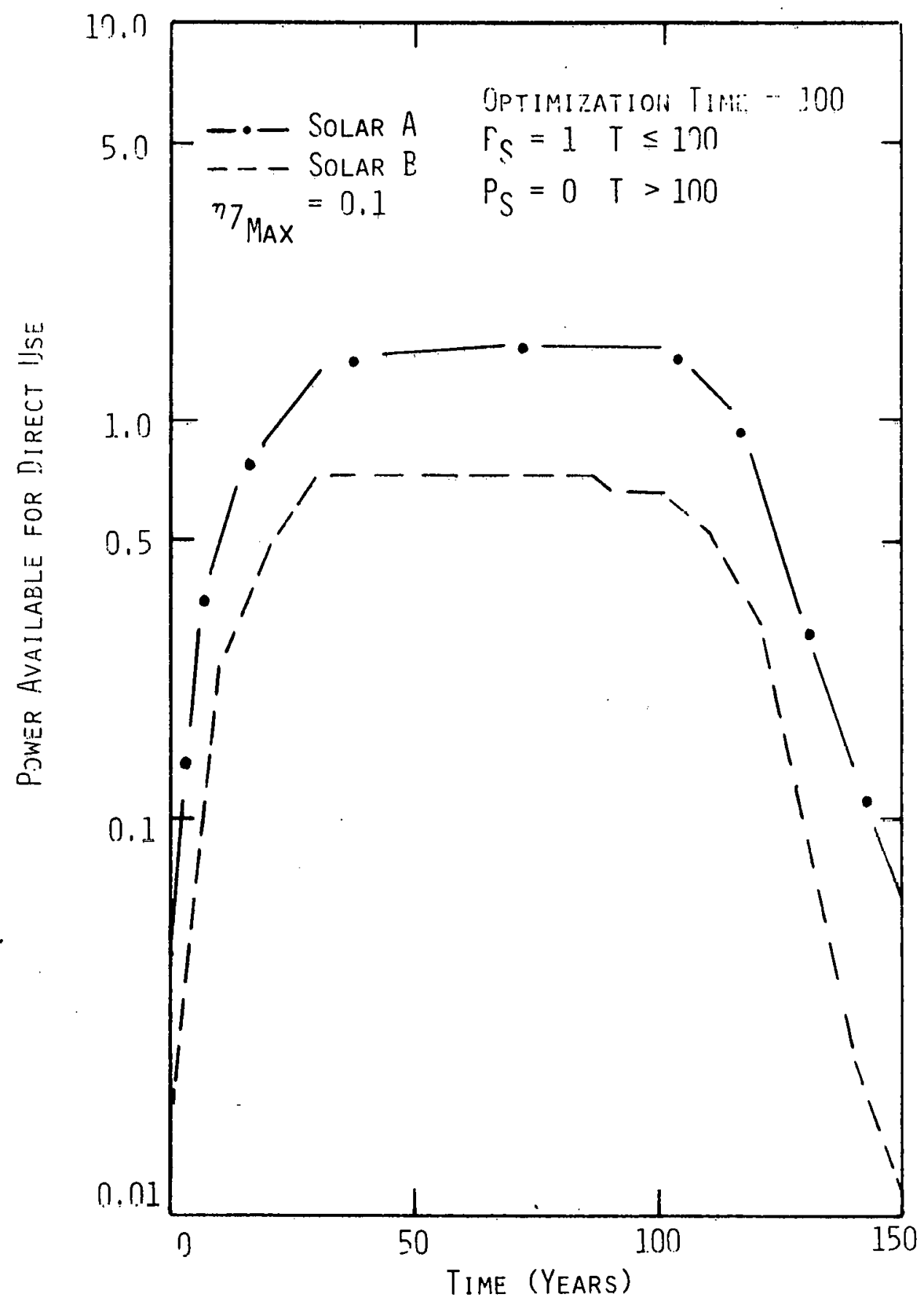

Figure 5. Uirect Use Power Availability with a Constrained Feedback Strategy for two Electrical Polver Generation Systems; A 100 Year Optimization 


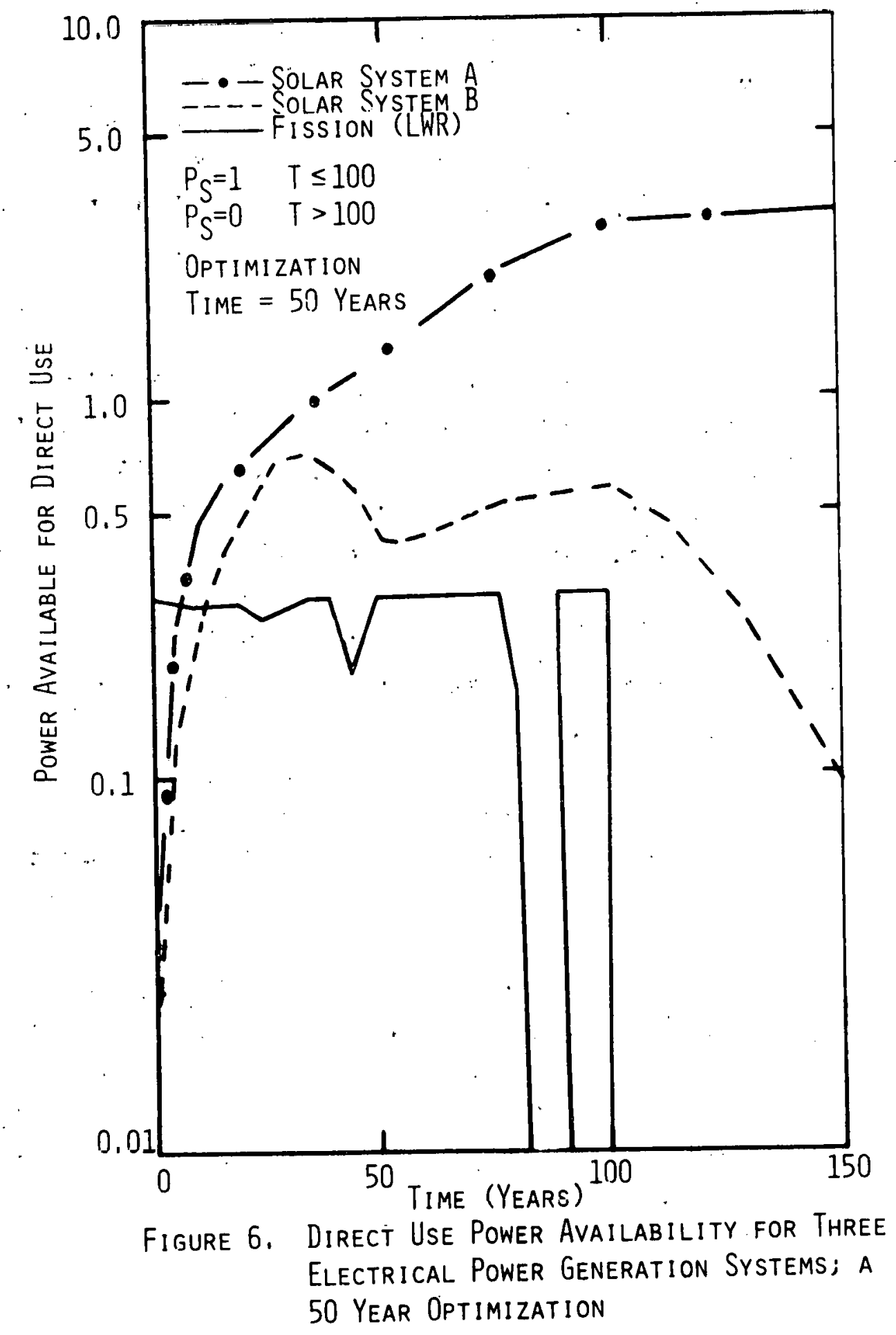


the low system efficiencies take over and the system begins to decay. Essentially no change occurs in the fission system, except the dramatic drop that occurs around 8.0 years into the simulation. The model is not being optimized here, therefore no planning is occurring. The available resources were used only to construct new capacity as the old capacity decayed. In no case did a 50 year planning period appear superior to a 100 year planning period. The shorter planning period affected solar $A$, the most promising system, more than any other.

The integrated energy efficiency is the total energy available for personal use divided by the total energy extracted from stored reserves during the optimization period. The integrated energy efficiencies are plulled as a functinn of the optimization period in Figure 7. Solar A produces approximately 5 times as much electrical power as consumed resource power. Solar $B$ is about $70 \%$ efficient and fission about 298 efficient. Solar A is almost 20 times more energy efficient than fission.

The effect of having a 20 year resource life, instead of 100 years, is shown in Figure 8. For the 20 year case, direct use power production drops $75 \%$ over a few years when resource consumption stops. All of the power produced by the system is needed for investment in future capacity. 75 years later the direct use power production is Inally ailieving the levels that il reached before the resource was consumed. If the lárge eneryy investmont liad mot bron made immeriately, the system would have decayed to zero. On the other hand, growth in direct use power does not change when the resource is exhausted after 100 years of subsidizing Solar A.

So far every case has shown Solar A to be a superior system to fission in energy efficiency, at least if society is capable of long term planning. Figure 9 may indicate some 


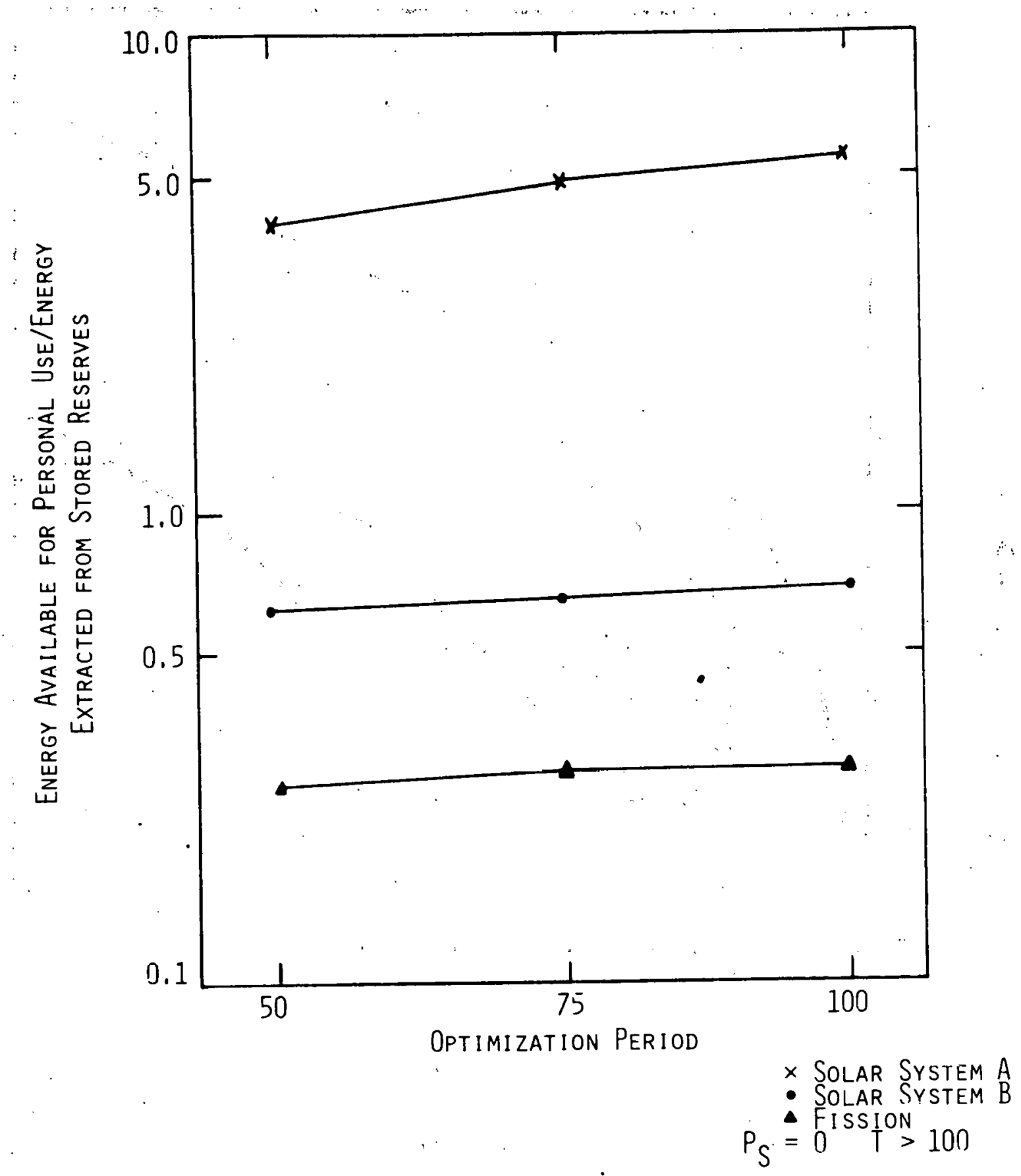

Figure 7. Relative Energy Efficiencies Over A 150 Year Conditioning Cycle 

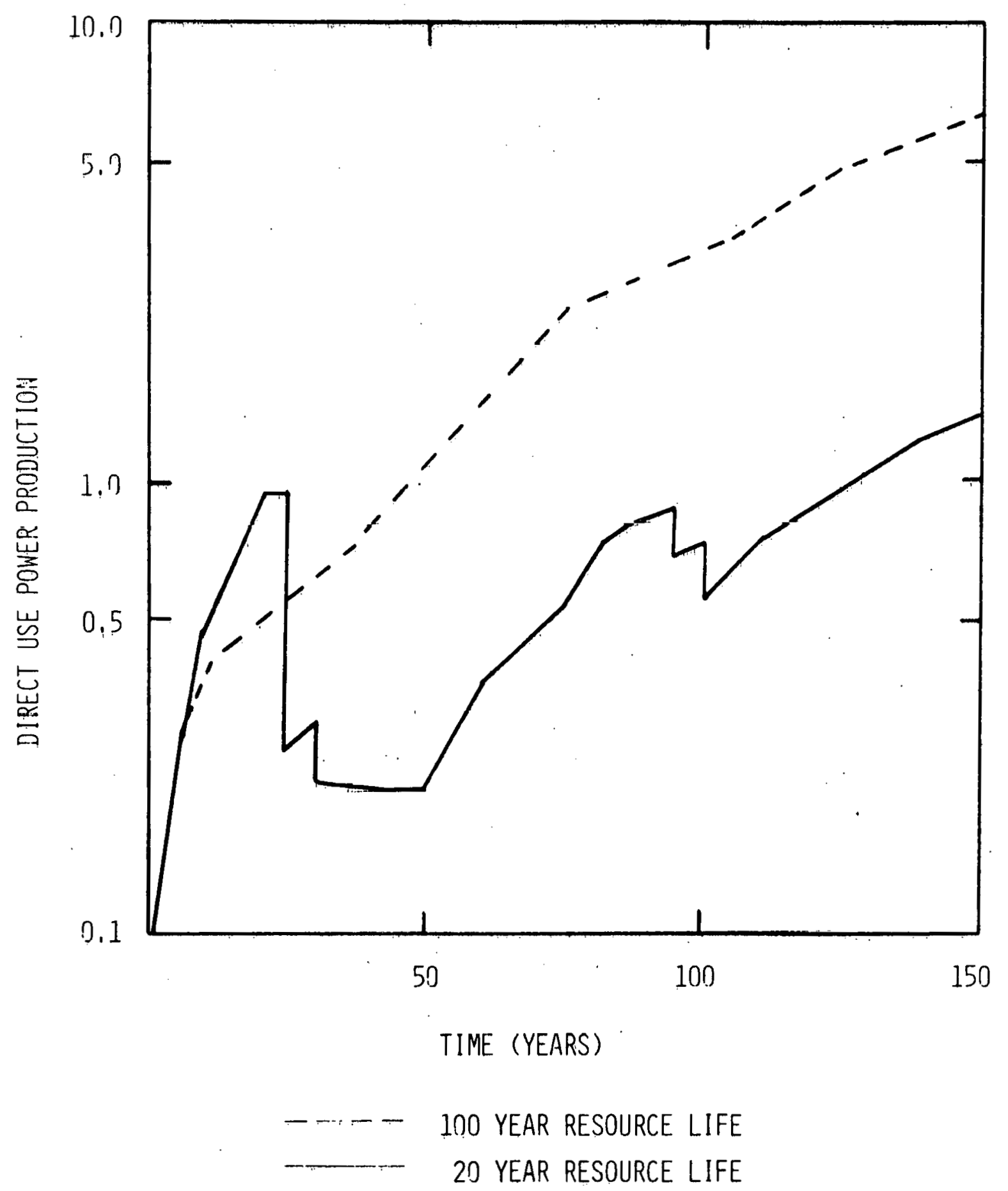

Figure 3. Optimization of Sular Sysiem A OVer 100 Years for Resource LifETIMES OF 20 AND 100 YeARS 


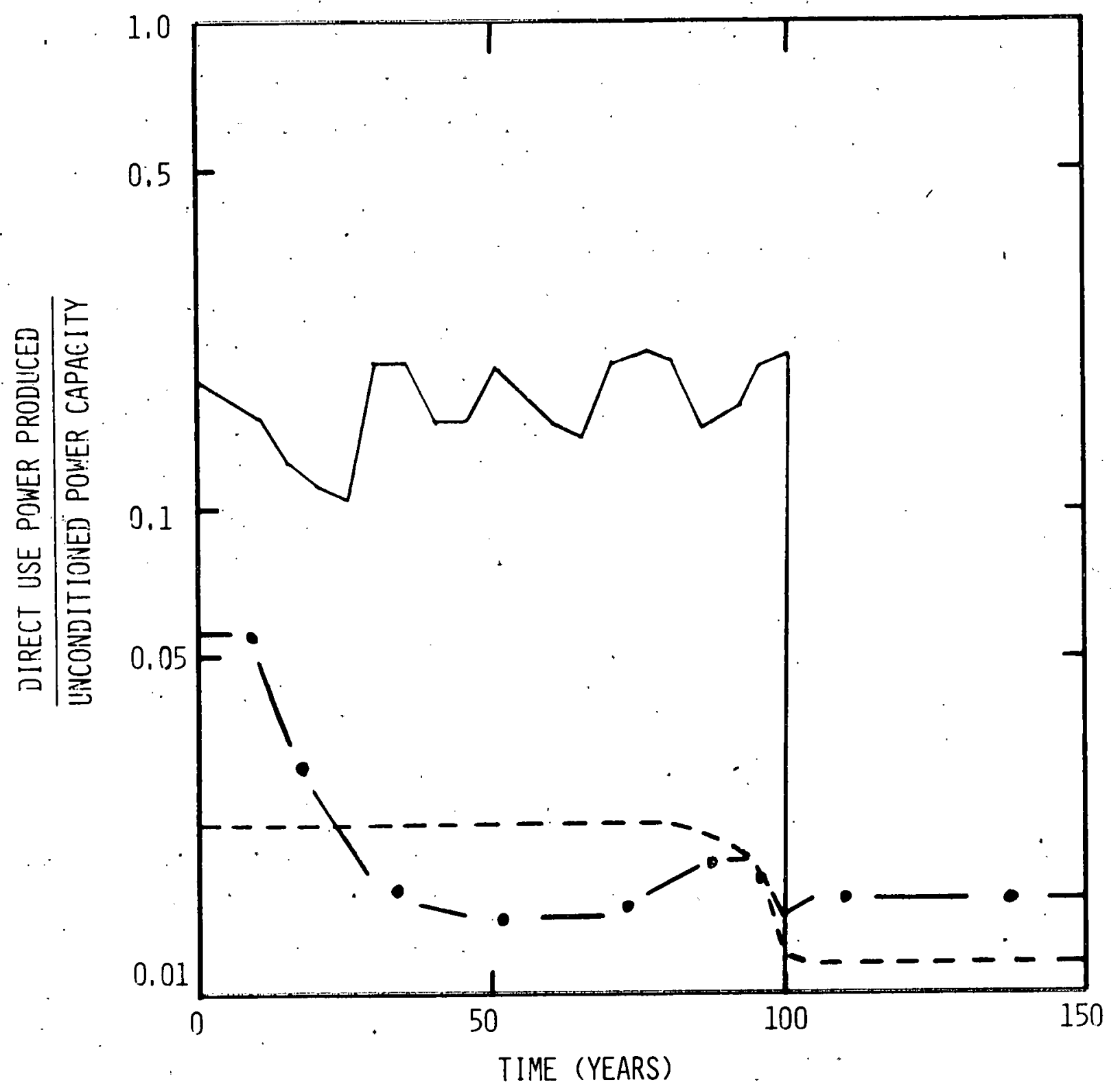

- - - SOLAR SYSTEM A

$\ldots$ SOLAR SYSTEM B

FISSION (LWR)

OPTIMIZATION $=100$ TIME

Figure 9. Mineral/Materials Resource Implications for Three Electrical Power generation Systems 
of the problems associated with Solar A. The ratio of direct use power produced to the operating units of unconditioned power capacity is plotted against time for a 100 year optimization. First, this illustrates that significantly more solar capacity may have to be installed per kilowatt hour produced. Secondly, if the materials required for a megawatt of unconditioned fission capacity are approximately equal to the materials required for a megawatt of unconditioned Solar A capacity, the materials requirements of solar A may be excessive. Approximately $17 \%$ of the unconditioned fission power capacity is available for direct use consumption. The average is approximately 1.68 for Solar A. This implies a Solar A material resource requirement at least 10 times greater than for fission power production. The material resource implications may be as serious for solar systems as the energy resource implications are for fission.

\section{Conclusions and Recommendations for Future Work}

The model as presented here is still in a rather preliminary form. However, it is believed that significant methodological advantages over alternative evaluation techniques for future energy sources are illustrated. The model is firmly based in physically confirmable energy efficiencies. If energy resources are finite, energy efficiencies must become a dominant factor in choosing power production techniques. The dynamic nature of the model presents the resulls effectively to planners who must work with a truly dynamic system. stintir modelc can lcad to a poor understanding of the importance of system efficiencies. The models are system, site, and application specific. The approach is equally applicable to general system characterizations and specific design evaluations. 
The implications of possible resource and societal constraints have been investigated. It is important to begin the introduction of new energy technologies long before resource constraints are reached. Energy resources are needed for subsidizing new technologies for a great number of years if smooth transitions are to take place. With new technologies, material resources may limit power production capacity rather than energy resources. More work must be done in the area of material resource constraints. The effects of recycling should also be investigated with this model.

Society may also institute constraints. Planning must be accomplished on a very long time scale. Sacrifices for the future must be made by reinvesting some direct use power into constructing new capacity. If sufficient resources are not reinvested, even superior systems may not be capable of sustaining themselves.

There are several directions that this work may take, from simple extensions to opening whole new areas of research. As a first step, estimates of system parameters for specific system designs should be obtained. Sensitivities of system performance with respect to system parameters should be calculated. The sensitivity analysis may indicate areas where small parameter improvements can lead to large system gains. Many other systems and system designs should be analyzed, preferably using the results of already completed net energy analyses. Breeder reactors and several fusion designs should be included. The effects of system design variations, such as MHD direct conversion and energy storage systems, should also be investigated.

Major extensions of this model should include incorporating material resource constraints into the model, and investigating the effect of recycling on these constraints. Finally, optimal strategies for resource allocation, both 
energy and materials, during a transition to new energy technologies should be investigated. This is envisioned as a two sector model, for example, fossil and solar, with a given fixed resource base. As the resource is consumed, the extraction efficiency drops. The results could provide interesting insights into allocating scarce, finite resources. 
1. Schipper, L. "Explaining Energy," Lawrence Berkeley Laboratory, LBL 4458, January 1976.

2. Herendeen, R. A., and Bullard, C. W., III, "Energy Costs of Goods and Services, 1963 and 1967," CAC Document No. 140, November 1974 .

3. Odum, H. T., "Environment, Power, and Society," Wiley,. New York, NY, 1971.

4. "A National Plan for Energy Research, Development and Demonstration: Creating Energy Choices for the Future," ERDA 99, Vol. 1, 1976.

5. Hooke, R., and Jeeves, T. A., "'Direct Search' Solution of Numerical and Statistical Problems," J. Ass. Comput. Mach., Vol. 8, 1961. 


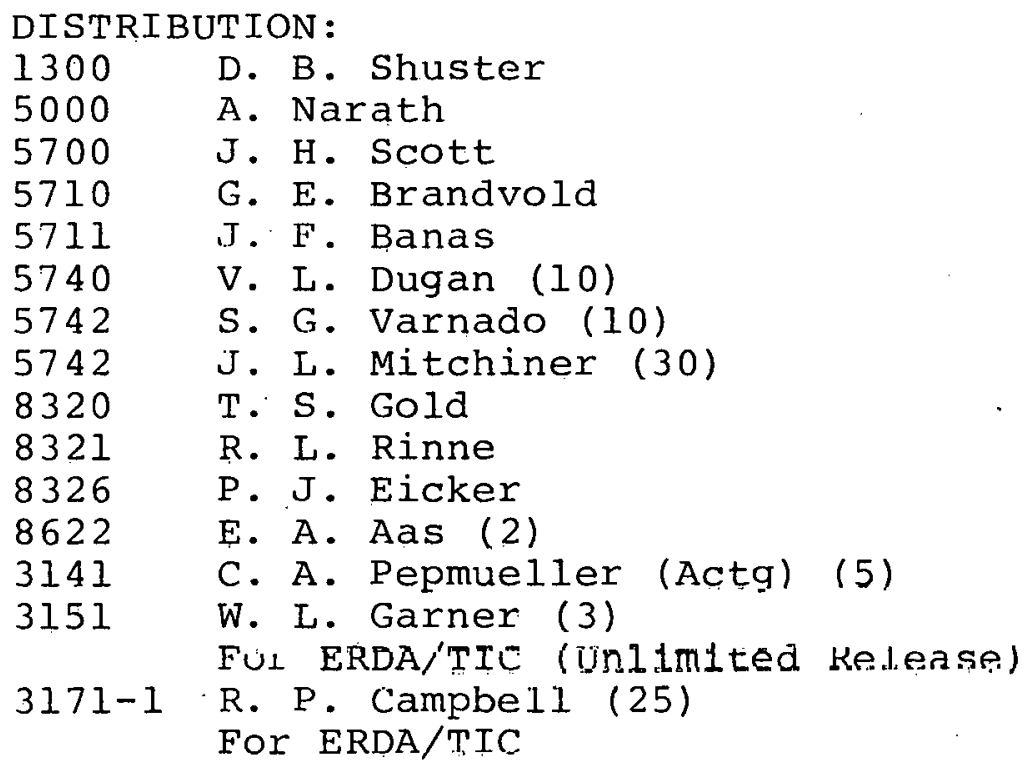




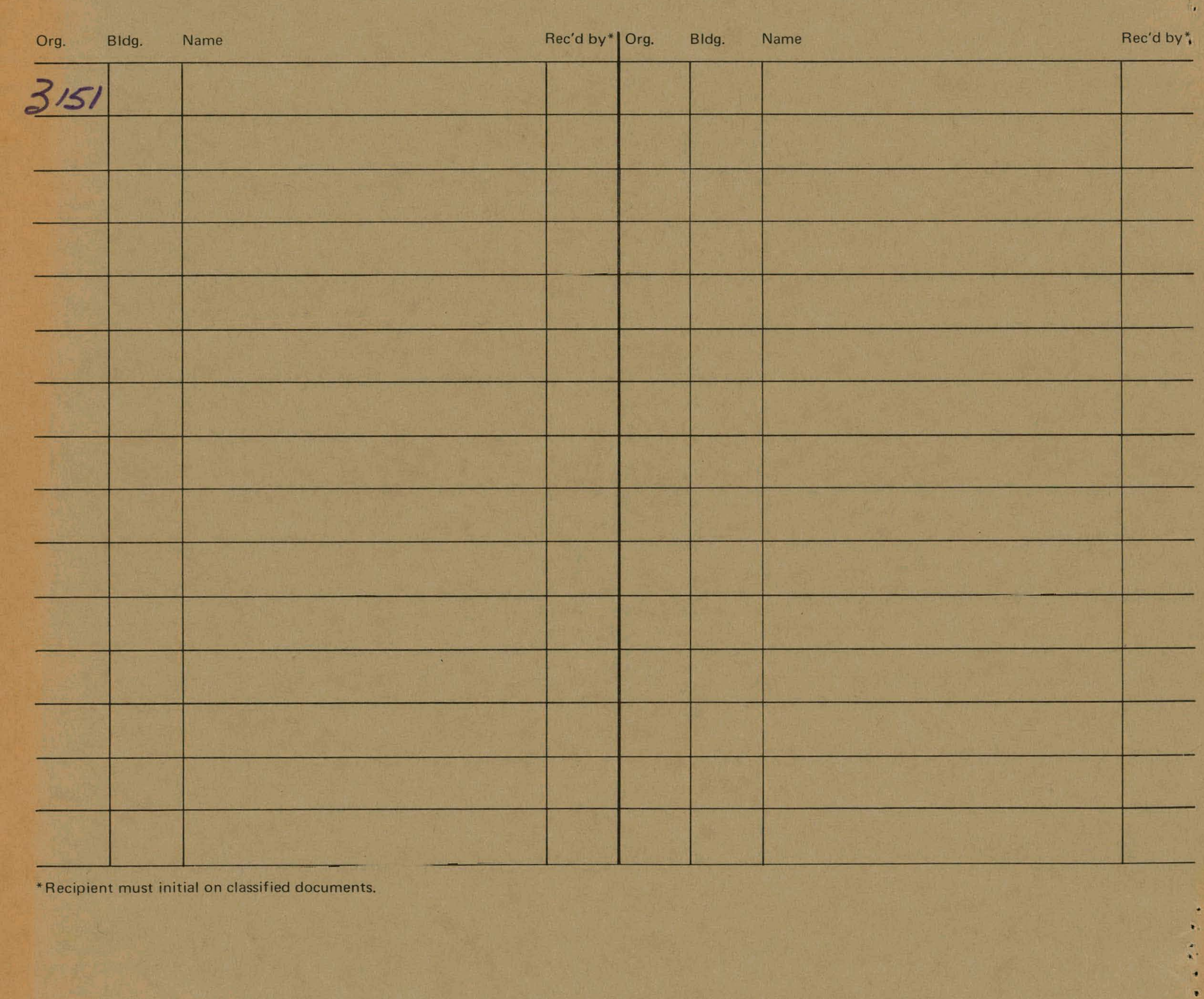

